\title{
LATE WASH CROSS-FLOW FILTER ORGANIC BALANCE (U)
}

\author{
WSRC-RP- $-92-1101$
}

by M. A. Saich

DE93 006880

Westinghouse Savannah River Company

Savannáh River Site

Aiken, South Carolina 29808

Other Authors:

\section{DISCLAIMER}

This report was prepared as an account of work sponsored by an agency of the United States Government. Neither the United States Government nor any agency thereof, nor any of their employees, makes any warranty, express or implied, or assumes any legal liability or responsibility for the accuracy, completeness, or usefulness of any information, apparatus, product, or process disclosed, or represents that its use would not infringe privately owned rights. Reference herein to any specific commercial product, process, or service by trade name, trademark, manufacturer, or otherwise does not necessarily constitute or imply its endorsement, recommendation, or favoring by the United States Government or any agency thereof. The views and opinions of authors expressed herein do not necessarily state or reflect those of the United States Government or any agency thereof.

This paper was prepared in connection with work done under Contract No. DE-AC09-89SR18035 with the U.S. Department of Energy. By acceptance of this paper, the publisher and/or recipient acknowledges the U.S. Government's right to retain a nonexclusive, royalty-free license in and to any copyright covering this paper, along with the ight to reproduce and to authorize others to reproduce all or part of the copyrighted paper. 


\section{DISCLAIMER}

This report was prepared as an account of work sponsored by an agency of the United States Government. Neither the United States Government nor any agency thereof, nor any of their employees, makes any warranty, express or implied, or assumes any legal liability or responsibility for the accuracy, completeness, or usefulness of any information, apparatus, product, or process disclosed, or represents that its use would not infringe privately owned rights. Reference herein to any specific commercial product, process, or service by trade name, trademark, manufacturer, or otherwise does not necessarily constitute or imply its endorsement, recommendation, or favoring by the United States Government or any agency thereof. The views and opinions of authors expressed herein do not necessarily state or reflect those of the United States Government or any agency thereof.

This report has been reproduced directly from the best available copy.

Available to DOE and DOE contractors from the Office of Scientific and Technical Information, P. O. Box 62, Oak Ridge, TN 37831; prices available from (615) $576-8401$.

Available to the public from the National Technical Information Service, U. S. Department of Commerce, 5285 Port Royal Rd., Springfield, VA 22161. 
Keywords: DWPF, Precipitate Hydrolysis, Late
Washing, Cross-Flow Filter, ITP

Retention Period: Permanent

CC: L. M. Papouchado, 773-A

W. L. Tamosaitis, 773-A

E. F. Duhn, 773-A

LuFtandon 704-T:

C. T. Randall, 704-T

J. T. Carter, 704-1T

M. D. Boersma, 704-T

D. L. Fish, 773-A

L. O. Dworjanyn, 779-2A

P. R. Monson, 704-iT

C. A. Nash, 786-5A

D. J. McCabe, 676-T

A. S. Choi, 704-1T

R. E. Eibling, 704-T

R. A. Jacobs, 704-T

J. C. Marek, 704-T

C. J. Bannochie, 704-1T

S. R. Young, 704-1T

M. F. Morrissey, 676-4T

SRTC Records (4)

November 16, 1992

TO: E. W. HOLTZSCHEITER, 773-A

FROM: M. A. BAICH, 704-T $m$. 8 .

LAIE WASH CBOSS-ELOW FILTER ORGANIC BALANCE (U)

\section{SUMMARY}

A recent DOE-SR review of the results and data from the Late Washing Crossilow Filter assessment identified the fate of biphenyl as a concern in the Late Washing material balance. The concern arose because after the late washing operation only about $40 \%$ of the biphenyl remained in the irradiated precipitate and analyses of the spent wash water stream did not account for the missing biphenyl [2]. This document summarizes the results of subsequent filtration studies on the behavior and fate of all known organic precipitate feed components including biphenyl. The study employed a statistically designed material balance across a laboratory crossflow filter. Data from two separate experiments are presented here.

Results of the first study indicated no statistically significant loss of biphenyl, diphenylmercury, O-terphenyl, diphenylamine, or aniline. Results did indicate minor losses of phenylboric acid, $M$-terphenyl, $P$-terphenyl, and a significant production of phenol, believed to be due to the way in which the experiment was performed. A second experiment demonstrated no statistically significant lose of any of the organic compounds.

Authorized Dorivative Classifier

C. T. Randall, 704-T 


\section{EXPERIMENTAL PROCEDURE}

To close the material balance for precipitate feed organics, a precipitate feed simulant was irradiated to an absorbed dose of $1.9 \mathrm{E}+08$ rads in the 774-A cobalt-60 source. After analytical characterization of the nitrite concentration, the nitrite concentration was adjusted $100.13 \mathrm{M}$ and then the soluble potassium and cesium were re-precipitated with sodium tetraphenylborate solution. Samples were taken for organic analysis. The material was then concentrated by circulating through a laboratory sintered metal crossflow fitter, removing filtrate without wash water makeup to a calculated $10 \mathrm{wt} \%$ insoluble solids. Batch washing was initiated by adding an aqueous solution of $0.004 \mathrm{M}$ sodium tetraphenylborate equal to the permeate collected. Samples of the washed precipitate and the permeate were taken and analyzed for organic materials. In the first experiment, permeate samples were taken during the wash cycle to determine permeate concentration profiles. In the second experiment, the total permeate was collected in one container and sampled. The fitter tube was then flushed and samples of the flush were taken and subsequently analyzed for organic materials.

\section{ANALYTICAL OBSERVATIONS}

The concentration of biphenyl in the permeate samples appeared to be constant with an average concentration of $27.5 \mathrm{ppm}$. In the first experiment, the soluble phenol concentration followed an exponential decline in concentration as would be expected for a continuous washing process. However, the phenol concentration of the last permeate sample was only about $23 \%$ of that detected in the slurry product. This indicates that a fraction of the phenol is trapped within the teraphenlyborate crystal matrix. This phenol may or may not slowly leach out during washing. No terphenyl's were detected in the permeate samples and only trace amounts of phenylboric acid were detected in the initial permeate samples. This indicates that the highly water soluble phenylboric acid is extensively trapped wit the solid crystal matrix and does not leach out during washing operations.

\section{MATERIAL BALANCE}

A statistical analysis was performed by T. B. Edwards of SRTC/NRTSC [3] (attached) to account for propagation of the random errors associated with the analytical and laboratory measurements. In the first experiment, the balance resulted in closure of the biphenyl, O-terphenyl, diphenylamine, aniline, and diphenylmercury at the $99 \%$ confidence interval. That is the " $99 \%$ confidenence interval for the unaccounted material" contained the value of zero. The " $99 \%$ confidence interval for the unaccounted material" for phenylboric acid, M-terphenyl, and P-terphenyl did not include the value of zero. This indicates a systematic loss of this component or a systematic analytical error. Although the analysis indicated a significant production of phenol during the washing operation, it is likely that this error is due to the numerical method used to perform the integration used in determining the total mass of phenol contained in the permeate.

Analysis of the data from the second experiment demonstrated no statistically significant losses of any of the organic compounds. Variability was higher but acceptable (in view of the fact that it is a mass balance on components present at $<0.5 \mathrm{wt} \%$ in a highly complex chemical system.) in the sample analyses for the second experiment.

\section{DISCUSSION}

Due to the exponential decline in the permeate phenol concentration for the first experiment, an integration of the total amount of phenol in the permeate was performed. An estimate of the variance was made by evaluating the degree to which the analytical data fit an exponential decline. The standard deviation was calculated to be $42.3 \mathrm{ppm}$ which is consistent with that of the other phenol analysis for that experiment. 
The $99 \%$ confidence interval for M-terphenyl and P-terphenyl did not include zero, which indicates a statistically significant amount unaccounted for in the first experiment. These results are possibly due to the extremely low levels of these components and the lack of there presence in the analytical standards on a routine basis. No statistically significant loss was observed in the second experiment.

\section{CONCLUSIONS}

The material balance has demonstrated that:

1) All of the terphenyl's and the majorit; of the phe aylboric acid (>95\%) in the irradiated feed to the Late Wash facility will be retained in the product slurry.

2) The majority $(\sim 2 / 3)$ of the phenol in the irradiated feed will be removed with the permeate from the Late Wash facility.

3) Minor amounts of biphenyl will be washed out of the slurny. The amount determined by the volume of wash and the solubility of the biphenyl (25-30 PPM).

4) The random errors associated with the analytical methods combined with the shear mass of material and low concentrations precludes the use of a material balance to determine the compounds responsible for the observed reduction in fitter flux ratesduring the Late Wash filtration process.

\section{RECOMMENDATIONS}

Investigate the chemical nature of the insoluble phenol and phenyboric acid in irradiated feed.

\section{REFERENCES}

1) Dworjanyn, L. O. and Morrissey, M. F., "Initial Technical Basis for the Use of Spare ITP Filter in DWPF Late Washing", WSRC-RP-92-766, June 5, 1992.

2) Morrissey, M. F., "Late Washing Efficiency", WSRC-RP-92-1030, August 31, 1992.

3) T. B. Edwards, "Statistical Analysis of Mass Balance Data", SCS-ASG-92082, October 16, 1992.

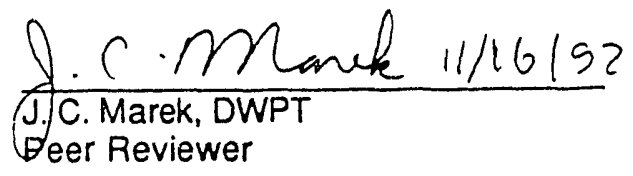


NRTSC

Technology

On Time

On Target

SCS-ASG-92082

October 16, 1992

Task 92-022-0

To: M. A. Baich,

704-T

J.C. Marek, 704-T

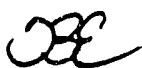

cc: L. F. Landon, 704-T

J.R. Pelfrey, 773-42A

ASG files, $773-42 A$

From: T.B. Edwards, 773-42A (5-5148)

$\frac{\text { At Peyrey }}{\text { R. Pelfrey, Manager }}$

Date: $10-27-92$

\section{STATISTICAL ANALYSIS OF MASS BALANCE DATA (U)}

\section{Introduction}

Data from the most recent Filter Tests (\#3 and \#4) completed at TNX were analyzed using statistical methods. The objective of this analysis was to complete a mass balance for each of the chemical compounds of interest for each of the tests.

To complete a mass balance for a test, the concentration of each compound as well as the total mass at each of four locations were used. These locations are feed slurry, product, flush, and filtrate. The material total at each of these locations is assumed known without appreciable error. The concentrations at each location are estimated based upon the experimental data. These values are used to estimate the unaccounted for mass of each compound. The uncertainty of this estimate is determined by propagating the variances of the estimates of the concentrations.

Seven samples of the feed slurry, product, flush, and filtrate were taken and anaiyzed. Tables $1 \mathrm{a}$ and $1 \mathrm{~b}$ in Appendix A provide these data and identify the chemical compounds of interest for Test \#3 and \#4, respectively. Values are given in parts per million (ppm) for all concentrations except the filtrate which is in micrograms/milliliter $(\mu \mathrm{g} / \mathrm{ml})$. 


\section{Estimation of the Unaccounted for Mass}

The following notation will be helpful in developing an appropriate model for the mass balance problem for a given compound for each of the two tests.

Let

Test \#3 Test \#4

$\begin{array}{rlllll}\mathrm{x} & = & \text { mass of feed slurry in grams }(\mathrm{g}) & = & 7,241 \mathrm{~g} & 15,238 \mathrm{~g} \\ \mathrm{y} & = & \text { mass of product in grams } & = & 5,577 \mathrm{~g} & 13,292 \mathrm{~g} \\ \mathrm{t} & = & \text { mass of flush in grams } & = & 3,473 \mathrm{~g} & 4,378 \mathrm{~g} \\ \mathrm{z} & = & \text { volume of filtrate in milliliters }(\mathrm{ml})= & 15,089 \mathrm{ml} & 36,385 \mathrm{ml}\end{array}$

and

$\begin{array}{lll}c_{x} & = & \text { estimated concentration of compound in feed slurry in ppm } \\ c_{y} & = & \text { estimated concentration of compound in product in ppm } \\ c_{t} & = & \text { estimated concentration of compound in flush in ppm } \\ c_{z}= & \text { estimated concentration of compound in filtrate in } \mu \mathrm{g} / \mathrm{ml}\end{array}$

If $u$ represents the unaccounted for mass of the compound in grams, then $u$ is estimated by

$$
\hat{u}=\frac{\left(x c_{x}-\left(y c_{y}+t c_{y}+z c_{z}\right)\right)}{10^{6}}
$$

The values of $c_{x}, c_{y}, c_{t}$, and $c_{z}$ and their uncertainties are estimated from the sample data. An example is used to demonstrate the approach. If $p_{i}$, for $i=1,2, \ldots, 7$, represents the seven feed slurry sample ppm values, then estimate $c_{x}$ is taken as the sample average of the $p_{i}$ 's. Thus,

$$
c_{x} \quad=\quad \sum_{i=1}^{7} \frac{p_{i}}{7}
$$

If the sample standard deviation of the $p_{i}$ 's is represented by $s_{p}$, then the standard deviation of the error of $c_{x}$ is estimated by $\frac{s_{p}}{\sqrt{7}}$ The other concentrations, except for the phenol filtrate concentration in Test \#3, are handled in a similar manner using the sample means and standard deviations in Tables $2 a$ and $2 b$ in Appendix $A$. Due to the method of filtrate sampling used in Test \#3, the estimations of the phenol concentration and the associated uncertainty had to be handled differently. The details of these estimations are provided in Appendix B.

Let $\sigma_{c x}$ represent the estimate of the standard deviation of the error for $c_{x}$, $\sigma_{c y}$ represent the estimate of the standard deviation of the error for $c_{y}$, $\sigma_{\mathrm{ct}}$ represent the estimate of the standard deviation of the error for $c_{1}$, and $\sigma_{c z}$ represent the estimate of the standard deviation of the error for $c_{z}$. 
The variance of $\hat{u}$ in equation (1) is determined via a propagation of variance. The errors in the values of $x, y, t$, and $z$ are assumed to be small compared with the errors in the concentrations. Data were not available to investigate bias or systematic errors in the sampling or analytical methods; these errors are assumed to be negligible. Errors in the measured concentrations are assumed to be inciependent. Since the error in $\hat{U}$ is a linear combination of independent, random error terms, the estimate of the standard deviation of $u$ is given by

$$
\delta_{u}=\sqrt{\left(\frac{x}{10^{6}} \sigma_{c x}\right)^{2}+\left(\frac{-y}{10^{6}} \sigma_{c y}\right)^{2}+\left(\frac{-t}{10^{6}} \sigma_{c t}\right)^{2}+\left(\frac{-z}{10^{6}} \sigma_{c z}\right)^{2}}
$$

A $99 \%$ confidence interval for $u$ is given by

$$
u \pm\left(t .005, v \times \delta_{u}\right)
$$

where $t .005, v$ represents the upper 0.5 percentile of Student's $t$ distribution with $v$ degrees of freedom.

Tables $3 a$ and $3 b$ provide an estimate of the unaccounted for mass of each compound along with a $99 \%$ confidence interval for Test \#3 and \#4, respectively. A negative value for the unaccounted for mass implies a processing "gain" for that particular chemical compound and a positive value a "loss." A significant "gain" for a compound would imply a bias in the sampling or analytical process for that compound while a significant "loss" indicates a bias in the measuring process or an unaccounted for deposit of the compound.

\section{Conclusions}

A confidence interval for the unaccounted for mass of each compound of interest has been determined. Some of these intervals for Test \#4 are very wide compared to Test \#3. This indicates a larger value for the estimate of the standard deviation, $\hat{\sigma}_{u}$, for $\hat{u}$. This is a result of the large variability of the concentration measurements of the samples within a location or process. Smaller confidence intervals would be expected if between sample variability could be reduced. Such a reduction may be possible via improvements in the sampling and/or analytical methods. An investigation into these methods could help identify opport. aities for such improvement as well as allow for the estimation of any bias errors. 
Appendix A: TABLES

Table 1a: Filter Test \#3 Data

Table 1b: Filter Test \#4 Data

Table 2a: Filter Test \#3 Sample Statistics

Table 2b: Filter Test \#4 Sample Statistics

Table 3a: Mass Balance Results for Filter Test \#3

Table 3b: Mass Balance Results for Filter Test \#4 
Table 1a: Filter Test \#3 Data

Unit $=$ parts per million $(\mathrm{ppm})$ for all results except Filtrate Unit for Filtrate $=$ micrograms $/$ milliliter $(\mu \mathrm{g} / \mathrm{ml})$

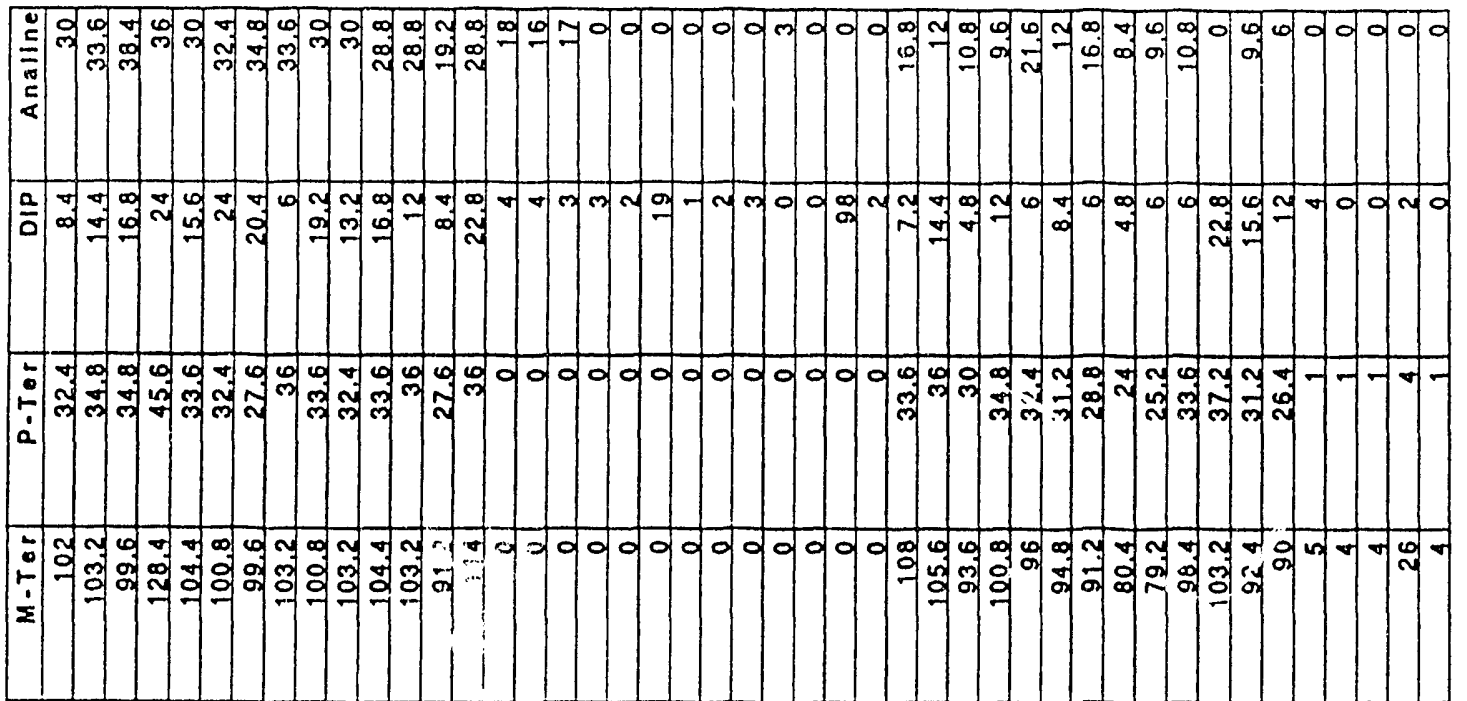

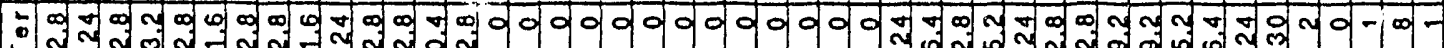

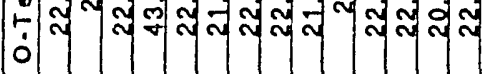

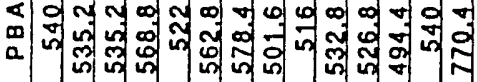

舟

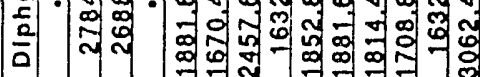

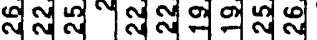

애 में क्ष

-

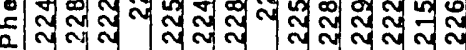

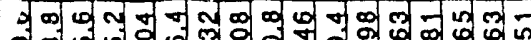

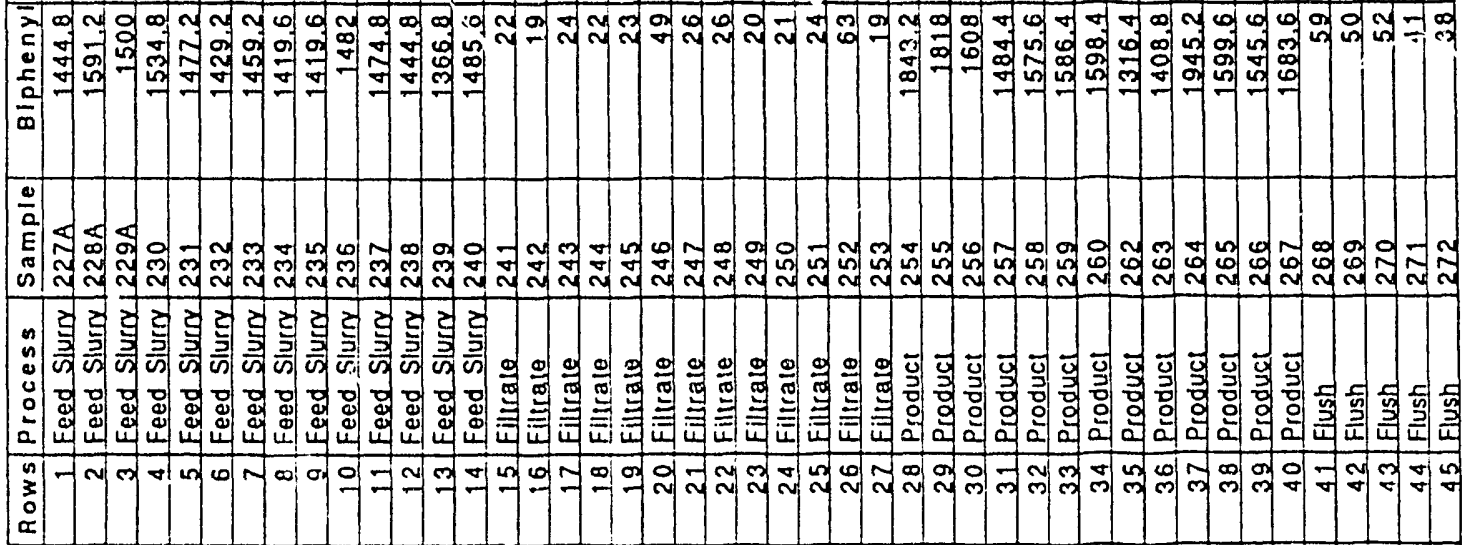


Table 1b: Filter Test \#4 Data

Unit = parts per million (ppm) for all results except Filtrate Unit for Filtrate $=$ micrograms $/$ milliliter $(\mu \mathrm{g} / \mathrm{ml})$

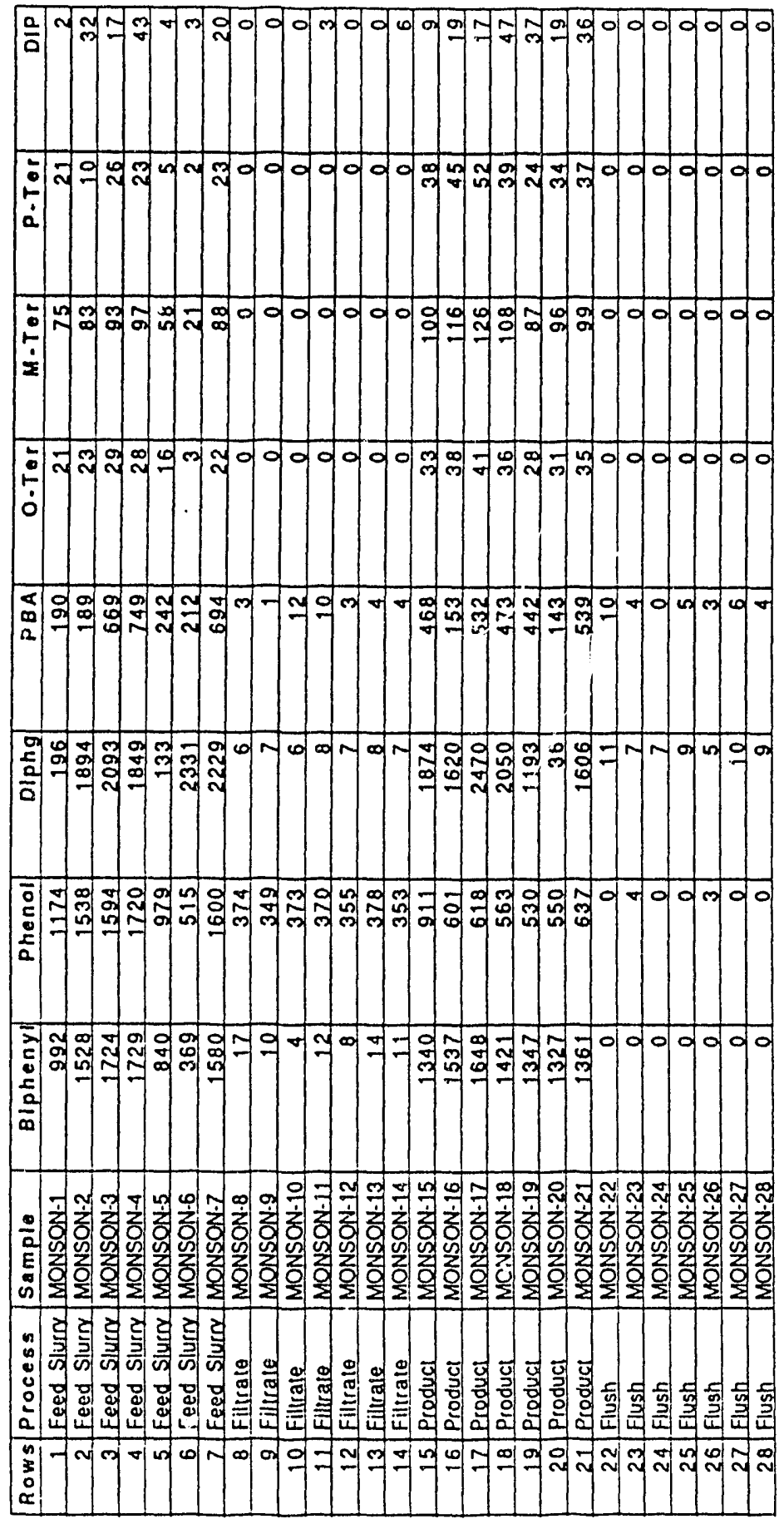


Table 2a: Filter Test \#3 Sample; Statistics

Unit $=$ parts per million (ppm) for all results except Filtrate Unit for Filtrate $=$ micrograms $/$ milliliter $(\mu \mathrm{g} / \mathrm{ml})$
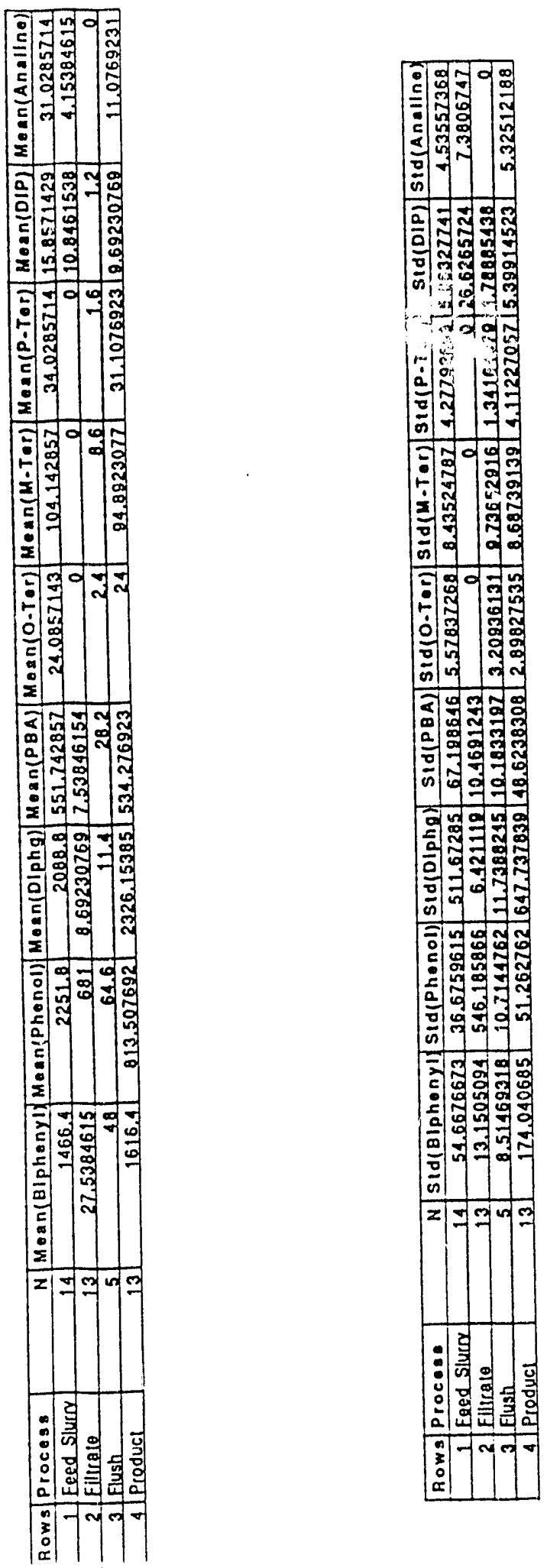
SCS-ASG-92082

Task 92-022-0

October $16,1: 2$

Page 8 of 18

Table 2b: Filter Tesi \#4 Sample Statistics

Unit $=$ parts per million $(\mathrm{ppm})$ for all results except Filtrate

Unit for Filtrate $=$ micrograms $/$ milliliter $(\mu \mathrm{g} / \mathrm{ml})$
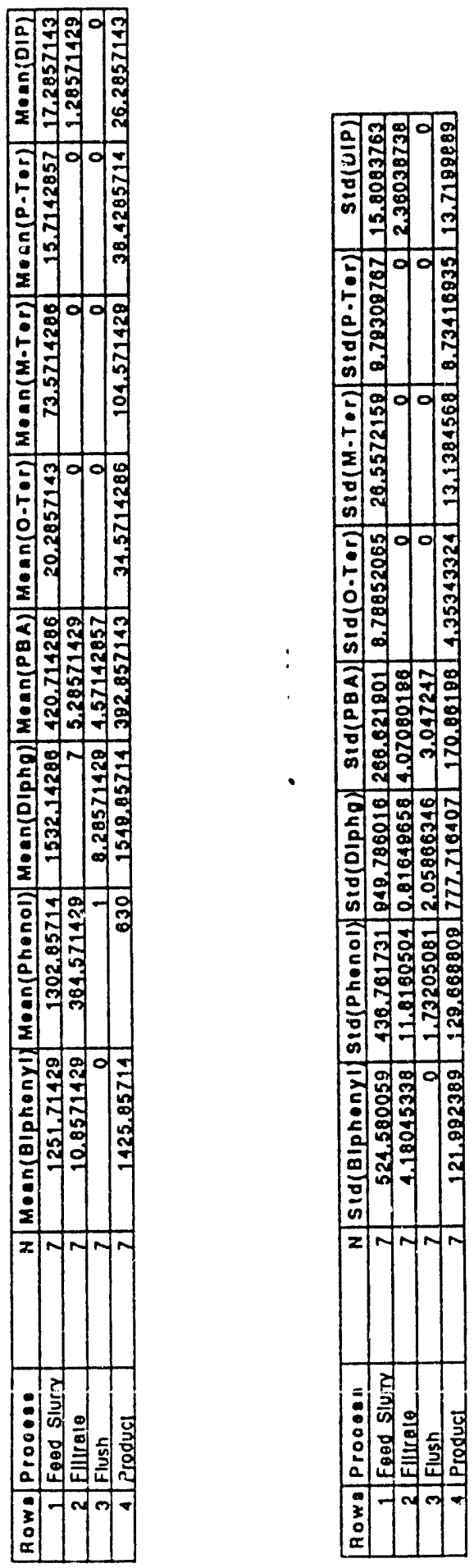
Table 3a: Mass Balance Results for Filter Test \#3

Total Mass - grams (except for Filtrate) - milliliters for Filtrate

Unaccounted For Mass (grams)
Sample Avg \& Sid Dev - ppm (except for Filtrate)

- micrograms/ml for Filtrate

\section{Bipheyl}

\begin{tabular}{|c|c|c|c|c|c|}
\hline & Feed Slurry & Product & Flush & Filtrate & Unaccounizd \\
\hline Mass(grams) & 7241 & 5643 & 3473 & 15089 & 0.9152037 \\
\hline Sample Conc & 1466.4 & 1616.4 & 48 & 27.5 & \\
\hline Sample STDev & 54.7 & 174 & 8.5 & 13.2 & 0.298 \\
\hline Sample Size & 14 & 13 & 5 & 13 & \\
\hline Degrees of & & & & & \\
\hline Freedom & 13 & 12 & 4 & 12 & 12 \\
\hline \multicolumn{6}{|c|}{$s 9 \%$ confidence interval for Unaccounted } \\
\hline & & 0.0059 & & 1.8245 & \\
\hline
\end{tabular}

PBA

\begin{tabular}{|c|c|c|c|c|c|}
\hline & Feed Slurry & Product & Flush & Filtrate & Unaccounted \\
\hline Mass(grams) & 7241 & 5643 & 3473 & 15089 & 0.7686987 \\
\hline Sample Conc & 551.7 & 534.3 & 28.2 & 7.5 & \\
\hline Sample STDev & 67.2 & 48.6 & 10.2 & 10.5 & 0.158 \\
\hline Sample Size & 14 & 13 & 5 & 13 & \\
\hline Degrees of & & & & & \\
\hline Freedom & 13 & 12 & 4 & 12 & 12 \\
\hline \multicolumn{6}{|c|}{$99 \%$ confidence interval for Unaccounted } \\
\hline & & 0.287 & & 1.251 & \\
\hline
\end{tabular}

DIPHG

\begin{tabular}{|c|c|c|c|c|c|}
\hline & Feed Slurry & Product & Flush & Filtrate & Unaccounted \\
\hline Mass(grams) & 7241 & 5643 & 3473 & 15089 & 1.8273877 \\
\hline Sample Conc & 2088.8 & 2326.2 & 11.4 & 8.7 & \\
\hline Sample STDev & 511.7 & 647.7 & 11.7 & 6.4 & 1.474 \\
\hline Sample Size & 12 & 13 & 5 & 13 & \\
\hline Degrees of & & & & & \\
\hline Freedom & 11 & 12 & 4 & 12 & 11 \\
\hline \multicolumn{6}{|c|}{$99 \%$ confidence interval for Unaccounted } \\
\hline & & -2.751 & & 6.406 & \\
\hline
\end{tabular}


Table 3a: Mass Balance Results for Filter TEst \#3 (con't)

Total Mass - grams (except for Filtrate) - milliliters for Filtrate
Sample Avg \& Std Dev - ppm (except for Filtrate)

- micrograms/ml for Filtrate

Unaccounted For Mass (grams)

\section{O-Ter}

Mass(grams)
Sample Conc
Sample STDev
Sample Size
Degrees of

Freedom

Feed Slurry
7241
24.1
5.6
14

13

$\begin{array}{rr}\text { Product } & \text { Flush } \\ 5643 & 3473 \\ 24 & 2.4 \\ 2.9 & 3.2 \\ 13 & 5 \\ & \\ 12 & 4\end{array}$

12

$\begin{array}{rr}\text { Filtrate } & \text { Unaccounted } \\ 15089 & 0.0307409 \\ 0 & \\ 0 & 0.013 \\ 13 & \\ 12 & \\ & 9\end{array}$

$99 \%$ confidence interval for Unaccounted

0.075

\section{M-Ter}

\begin{tabular}{|c|c|c|c|c|c|}
\hline & Feed Slurry & Product & Flush & Filtrate & Unaccounied \\
\hline Mass(grams) & . $\quad 7241$ & 5643 & 3473 & 15089 & 0.1883996 \\
\hline Sample Conc & 104.1 & 94.9 & 8.6 & 0 & \\
\hline Sample STDev & 8.4 & 8.7 & 9.7 & 0 & 0.026 \\
\hline Sample Size & 14 & 13 & 5 & 13 & \\
\hline $\begin{array}{l}\text { Degrees of } \\
\text { Freedom }\end{array}$ & & 12 & 4 & 12 & 5 \\
\hline \multicolumn{6}{|c|}{$99 \%$ confidence interval for Unaccounted } \\
\hline & & 0.084 & & 0.293 & \\
\hline
\end{tabular}

\section{P-Ter}

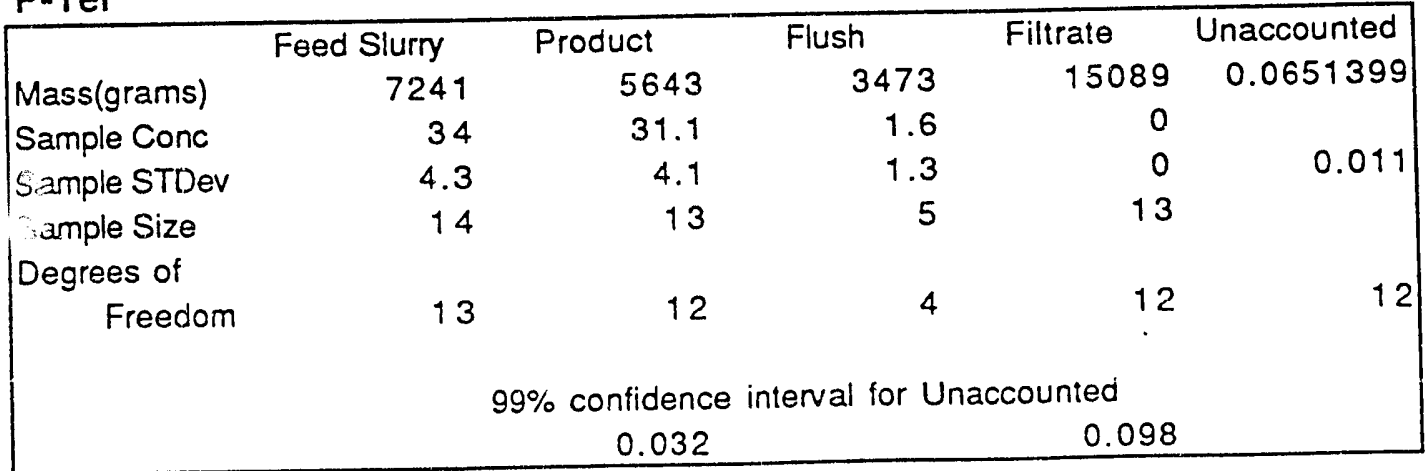


Table 3a: Mass Balance Results for Filter Test \#3 (con't)

Total Mass - grams (excep' for Filtrate) - milliliters ior Filtrate

Unaccounted For Mass (grams)
Sample Alg \& Std Dev - ppm (except for Filtrate)

- micrograms/ml for Filtrate

\section{DIP}

\begin{tabular}{|c|c|c|c|c|c|}
\hline & Feed Slurry & Product & Flush & Filtrate & Unaccounted \\
\hline Mass(grams) & 7241 & 5643 & 3473 & 15089 & -0.106734 \\
\hline Sample Conc & 15.9 & 9.7 & 1.2 & 10.8 & \\
\hline Sample STDev & 5.9 & 5.4 & 1.8 & 26.6 & 0.112 \\
\hline Sample Size & 14 & 13 & 5 & 13 & \\
\hline Degrees of & & & & & \\
\hline Freedom & 13 & 12 & 4 & 12 & 12 \\
\hline \multicolumn{6}{|c|}{$99 \%$ confidence interval for Unaccounted } \\
\hline & & -0.450 & & 0.236 & \\
\hline
\end{tabular}

\section{Analine}

\begin{tabular}{|lrrrrr|}
\hline & Feed Slurry & Product & \multicolumn{1}{c|}{ Flush } & Filtrate & Unaccounted \\
Mass(grams) & 7241 & 5643 & 3473 & 15089 & 0.0984599 \\
Sample Conc & 31 & 11.1 & 0 & 4.2 & \\
Sample STDev & 4.5 & 5.3 & 0 & 7.4 & 0.033 \\
Sample Size & 14 & 13 & 5 & 13 & \\
Degrees of & 13 & 12 & 4 & 12 & 12 \\
$\quad$ Freedom & 13 & & \\
& $99 \%$ confidence interval for Unaccounted \\
& -0.003 & 0.200 & \\
&
\end{tabular}

\section{Phenol}

\begin{tabular}{|c|c|c|c|c|c|}
\hline & Feed Slurry & Product & Flush & Filtrate & Unaccounted \\
\hline Mass(grams) & 7241 & 5643 & 3473 & 15089 & -3.3285594 \\
\hline Sample Conc & 2251.8 & 813.5 & 64.6 & 982.1 & \\
\hline Sample STDev & 36.7 & 51.3 & 10.7 & 44.5 & 0.680 \\
\hline Sample Size & 14 & 13 & 5 & 13 & \\
\hline Degrees of & & & & & \\
\hline Freedom & 13 & 12 & 4 & 11 & 11 \\
\hline \multicolumn{6}{|c|}{$99 \%$ confidence interval for Unaccounted } \\
\hline
\end{tabular}


Table 3b: Mass Balance Results for Filter Test \#4

Total Mass - grams (except for Filtrate) - milliliters for Filtrate
Sample Avg \& Std Dev - ppm (except for Filtrate)

- micrograms/mi for Filtrate

Unaccounted For Mass (grams)

Bipheyl

\begin{tabular}{|c|c|c|c|c|c|}
\hline & Feed Slurry & Product & Flush & Filtrate & Unaccounted For \\
\hline Total Mass & 15238 & 13292 & 4378 & 36385 & -0.2763 \\
\hline Sample Avg Conc & 1251.7 & 1425.9 & 0 & 10.9 & \\
\hline Sample Std Dev & 524.6 & 122 & 0 & 4.2 & 3.083 \\
\hline Sample Size & 7 & 7 & 7 & 7 & \\
\hline Degrees of & & & & & \\
\hline Freedom & 6 & 6 & 6 & 6 & \\
\hline \multicolumn{6}{|c|}{$99 \%$ confidence interval for Unaccounted For } \\
\hline & & -11.7067 & & 11.1542 & \\
\hline
\end{tabular}

\section{PBA}

\begin{tabular}{|c|c|c|c|c|c|}
\hline & Feed Slurry & Product & Flush & Filtrate & Unaccounted For \\
\hline Total Mass & 15238 & 13292 & 4378 & 36385 & 0.9752 \\
\hline Sample Avg Conc & 420.7 & 392.9 & 4.6 & 5.3 & \\
\hline Sample Std Dev & 266.6 & 170.9 & 3 & 4.1 & 1.76 \\
\hline Sample Size & 7 & 7 & 7 & 7 & \\
\hline Degrees of & & & & & \\
\hline Freedom & 6 & 6 & 6 & 6 & \\
\hline \multicolumn{6}{|c|}{$99 \%$ confidence interval for Unaccounted For } \\
\hline & & -5.550 & & 7.500 & \\
\hline
\end{tabular}

DIPHG

\begin{tabular}{|c|c|c|c|c|c|}
\hline & Feed Slurry & Product & Flush & Filtrate & Unaccounted For \\
\hline Total Mass & 15238 & 13292 & 4378 & 36385 & 2.4538 \\
\hline Sample Avg Conc & 1532.1 & 1549.9 & 8.3 & 7 & \\
\hline Sample Std Dev & 949.8 & 777.7 & 2.1 & 0.82 & 6.722 \\
\hline Sample Size & 7 & 7 & 7 & 7 & \\
\hline Degrees of & & & & & \\
\hline Freedom & 6 & 6 & 6 & 6 & 6 \\
\hline \multicolumn{6}{|c|}{$99 \%$ confidence interval for Unaccounted For } \\
\hline & & -22.466 & & 27.373 & \\
\hline
\end{tabular}


Table 3b: Mass Balance Results for Filter Test \#4 (con't)

Total Mass - grams (except for Filtrate) - milliititers for Filtrate
Sample Avg \& Std Dev - ppm (except for Filtrate)

- micrograms/ml for Filtrate

Unaccounted For Mass (grams)

O-Ter

\begin{tabular}{|lrrrrr|}
\hline & Feed Slurry & Product & Flush & Filtrate & Unaccounted For \\
Total Mass & 15238 & 13292 & 4378 & 36385 & -0.1506 \\
Sample Avg Conc & 20.3 & 34.6 & 0 & 0 & \\
Sample Std Dev & 8.8 & 4.4 & 0 & 0 & 0.055 \\
Sample Size & 7 & 7 & 7 & 7 & \\
Degrees of & 6 & 6 & 6 & 6 \\
$\quad$ Freedom & 6 & 6 & & \\
& & & \\
& $99 \%$ confidence interval for Unaccounted For \\
& -0.356 & 0.054 & \\
\hline
\end{tabular}

M-Ter

\begin{tabular}{|c|c|c|c|c|c|}
\hline & Feed Slurry & Product & Flush & Filtrate & Unaccounted For \\
\hline Total Mass & 15238 & 13292 & 4378 & 36385 & -0.2688 \\
\hline Sample Avg Conc & 73.6 & 104.6 & 0 & 0 & \\
\hline Sample Std Dev & 26.6 & 13.1 & 0 & 0 & 0.167 \\
\hline Sample Size & 7 & 7 & 7 & 7 & \\
\hline Degrees of & & & & & \\
\hline Freedom & 6 & 6 & 6 & 6 & 6 \\
\hline \multicolumn{6}{|c|}{$\%$ confidence interval for Unaccounted For } \\
\hline
\end{tabular}

P-Ter

\begin{tabular}{|lrrrrr|}
\hline & Feed Slurry & \multicolumn{1}{c}{ Product } & Flush & Filtrate & Unaccounted For \\
Total Mass & 15238 & 13292 & 4378 & 36385 & -0.2712 \\
Sample Avg Conc & 15.7 & 38.4 & 0 & 0 & \\
Sample Std Dev & 9.8 & 8.7 & 0 & 0 & 0.071 \\
Sample Size & 7 & 7 & 7 & 7 & \\
$\begin{array}{l}\text { Degrees of } \\
\quad \text { Freedom }\end{array}$ & 6 & 6 & 6 & 6 & 6 \\
& \multicolumn{5}{c}{$99 \%$ confidence interval for Unaccounted For } \\
& -0.536 & -0.007 & \\
& & &
\end{tabular}


Table 3b: Mass Balance Results for Filter Test \#4 (con't)

Total Mass - grams (except for Filtrate) - milliliters for Filtrate

Unaccounted For Mass (grams)
Sample Avg \& Sid Dev - ppm (except for Filtrate)

- micrograms/mi for Filtrate

DIP

\begin{tabular}{|c|c|c|c|c|c|}
\hline & Feed Slurry & Produc: & Flush & Filtrate & Unaccounted For \\
\hline Total Mass & 15238 & 13292 & 4378 & 36385 & -0.1333 \\
\hline Sample Avg Conc & 17.3 & 26.3 & 0 & 1.3 & \\
\hline Sample Std Dev & 15.8 & 13.7 & 0 & 2.4 & 0.119 \\
\hline Sample Size & 7 & 7 & 7 & 7 & \\
\hline Degrees of & & & & & \\
\hline Freedom & 6 & 6 & 6 & 6 & 6 \\
\hline \multicolumn{6}{|c|}{$99 \%$ confidence interval for Unaccounted For } \\
\hline & & -0.574 & & 0.307 & \\
\hline
\end{tabular}

\section{Phenol}

\begin{tabular}{|c|c|c|c|c|c|}
\hline & Fo d Slurry & Product & Flush & Filtrate & Unaccounted For \\
\hline Total Mass & 15,38 & 13292 & 4378 & 36385 & -1.7907 \\
\hline Sample Avg Conc & 1302.9 & 630 & 1 & 364.6 & \\
\hline Sample Std Dev & 436.8 & 129.7 & 1.7 & 11.8 & 2.604 \\
\hline Sample Size & 7 & 7 & 7 & 7 & \\
\hline Degreas of & & & & & \\
\hline Freedom & 6 & 6 & 6 & 6 & 6 \\
\hline \multicolumn{6}{|c|}{$99 \%$ confidence interval for Unaccounted For } \\
\hline & & -11.443 & & 7.862 & \\
\hline
\end{tabular}


Appendix B: $\quad$ Test \#3 Filtrate Phenol Sample Results

The method of sampling the filtrate for Test \#3 was different from that for Test \#4. In test \#3, the filtrate stream was sampled during the processing, whereas in Test \#4 the sampling was performed from a container holding the filtrate after completion of the processing. The phenol results are very sensitive to the method used for Test \#3; this is seen in the data in Table 1a of Appendix A. These data decrease significantly over time.

The following method was used to estimate an "average" concentration of phenol in the filtrate samples. The relationship between phenol concentration and time is represented in Figure 1 below.

Figure 1: Phenol Concentration vs Filtrate Volume Concentration - micrograms/milliliter

Volume - milliliters

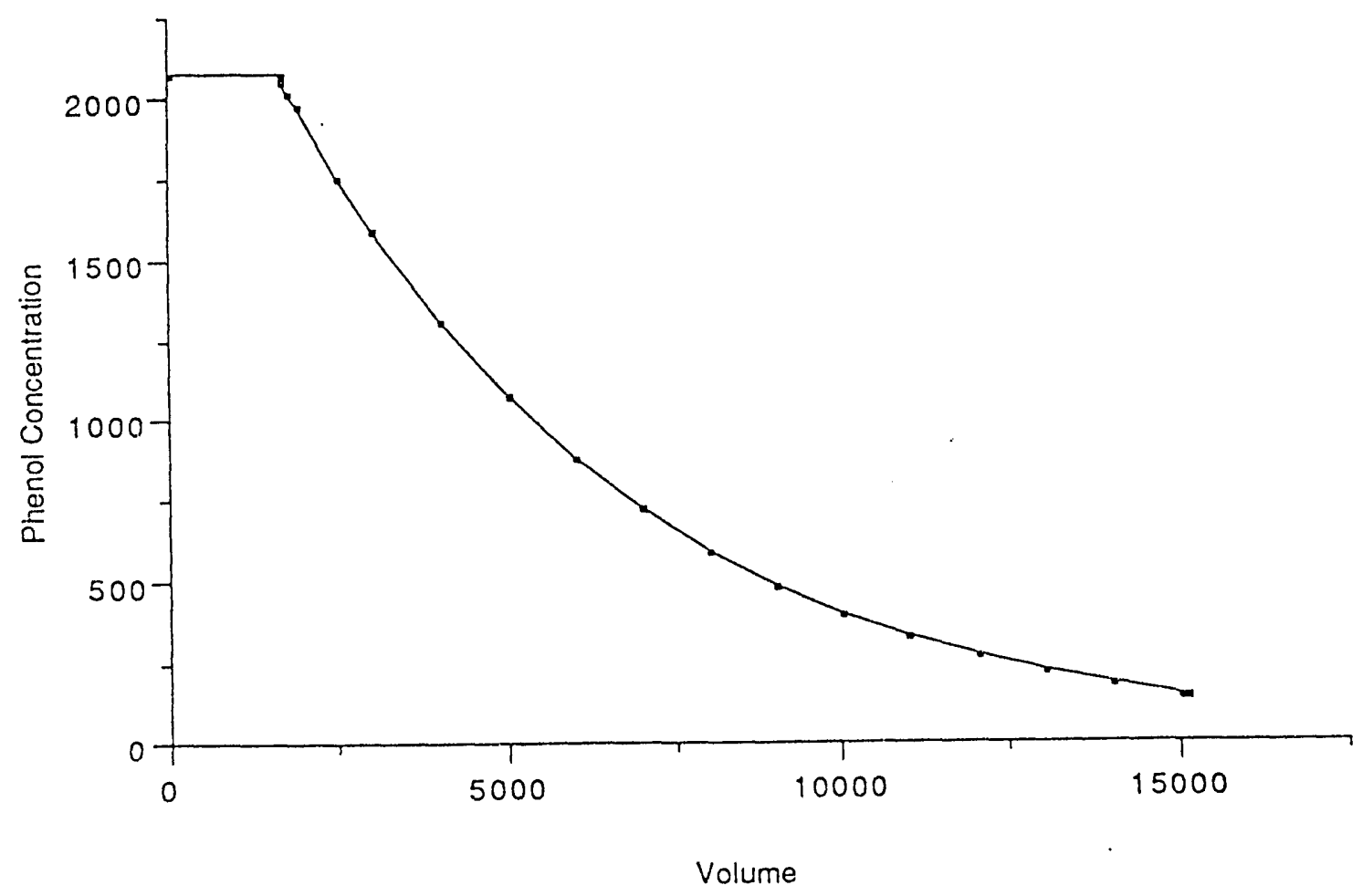


This figure shows a stable phenol concentration in the filtrate until a volume of $1663 \mathrm{ml}$ had been generated at which time the concentration begins to decline like a first order exponential. Let $A$ be the area under the curve of Figure 1; then, the relationship to the average phenol concentration, $a$, is estimated by

$$
15089 \mathrm{a}=\mathrm{A}
$$

To estimate the portion of area $A$ under the exponential curve, an exponential model was fitted to the phenol filtrate sample data. This was accomplished by performing a linear fit to the natural $\log (L N)$ of these data. The results of this fit are presented in Exhibit 1.

EXHIBIT 1: LN (Phenol) versus Corrected Cumulative Permeate Volume

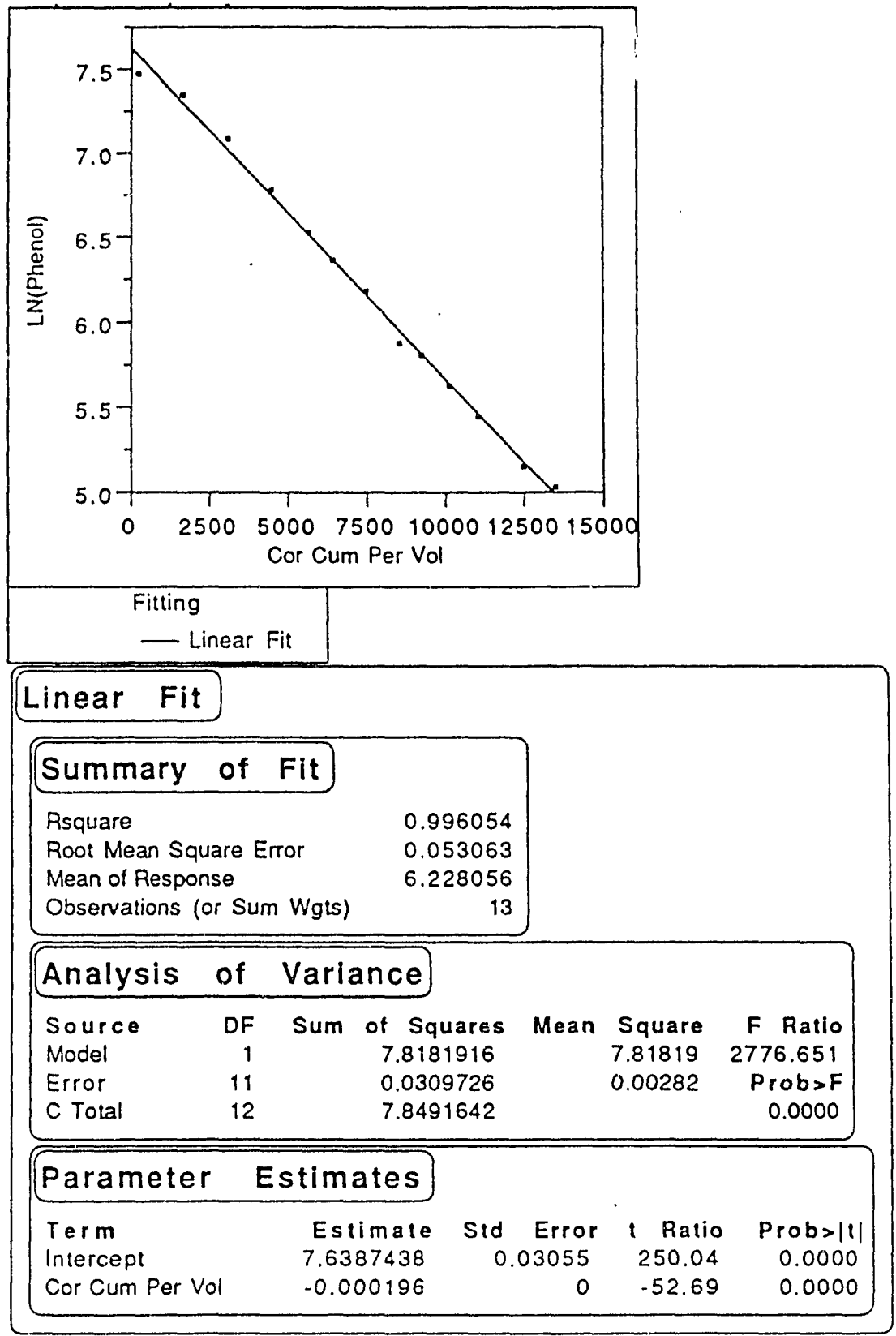


The estimated exponential model is given by

$$
\begin{aligned}
\text { Phenol Concentration at Volume } v & =e^{7.639} e^{-0.000196(v-1663)} \\
& =2,077.7 e^{-0.000196(v-1663)}
\end{aligned}
$$

The area under the exponential portion of Figure 1 , call this area $A_{1}$, is given by

$$
A_{1}=\int_{1663}^{15089} 2077.7 e^{-0.000196(v-1663)} d v=11,363,436.5
$$

The estimate of the concentration at a filtrate volume of $1663 \mathrm{ml}$ is $2077.7 \mu \mathrm{g} / \mathrm{ml}$. Thus, the estimate of the area under the rectangular portion of Figure 1, call this are $a A_{2}$, is given by

$$
A_{2}=2,077.7 \times 1663=3,455,215.1
$$

The total area under the curve of Figure 1 is $14,818,651.6$ and thus the estimate of a, the phenol concentration for the filtrate, is $982.1 \mu \mathrm{g} / \mathrm{ml}$.

The variance, $\sigma^{2}$, of this estimate of phenol concentration is given by

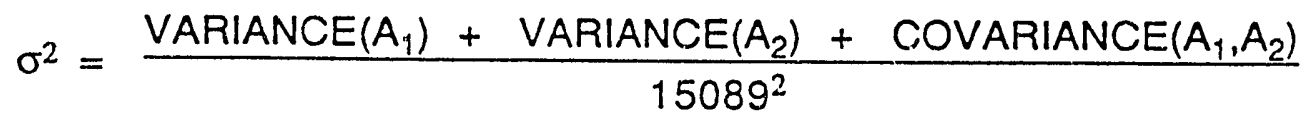

These variances and covariances will be estimated from the results of the exponential model fitted to the phenol sample values. The root mean square error of 0.053 provides an estimate of the relative error of the phenol concentration at a filtrate volume over $1663 \mathrm{ml}$. Thus, the relative standard deviation of the error in the phenol concentration is $5.3 \%$. This translates into a $5.3 \%$ relative standard error in the value of $A_{1}$. For the value of $A_{1}=11,363,436.5$, the standard error is $602,262.1$.

Area $A_{2}$ is based on the estimate of the intercept from the exponential fit. The standard error of the estimate of the intercept is 0.031 with degrees of freedom equal to 11 . Thus, a 95\% confidence interval for the intercept is given by

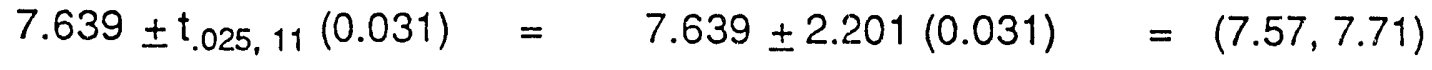

where $t_{.025,11}$ is the upper 2.5 percentile for the Student's $t$ distribution with 11 degrees of freedom.

Using the limits of this interval, a $95 \%$ confidence interval for $A_{2}$ is computed as follows 


$$
\left(1663 \times \mathrm{e}^{7.57}, 1663 \times \mathrm{e}^{7.71}\right)=(3,224,790 ; 3,709,392)
$$

This confidence interval can be used to estimate the standard error of $A_{2}$ since 4 times the standard error is approximately the width of this interval, or

$$
\text { Standard Error of } A_{2}=\frac{(3,709,392-3,224,790)}{4}=121,151
$$

The covariance for $A_{1}$ and $A_{2}$ will be estimated by the product of the standard errors for $A_{1}$ and $A_{2}$ or

$$
\text { COVARIANCE }\left(A_{1}, A_{2}\right)=602,262.1 \times 121,151
$$

Finally, the variance of the estimate of the phenol concentration is given by

$$
\begin{aligned}
\sigma^{2} & =\frac{\operatorname{VARIANCE}\left(A_{1}\right)+\operatorname{VARIANCE}\left(A_{2}\right)+\operatorname{COVARIANCE}\left(A_{1}, A_{2}\right)}{15089^{2}} \\
& =\operatorname{IF}\left(602,262.1^{2}+121,151^{2}+(121,151 \times 602,262.1), 15089^{2}\right) \\
& =1978
\end{aligned}
$$

Thus, the standard error of the estimate of the phenol concentration is given by 44.5. 

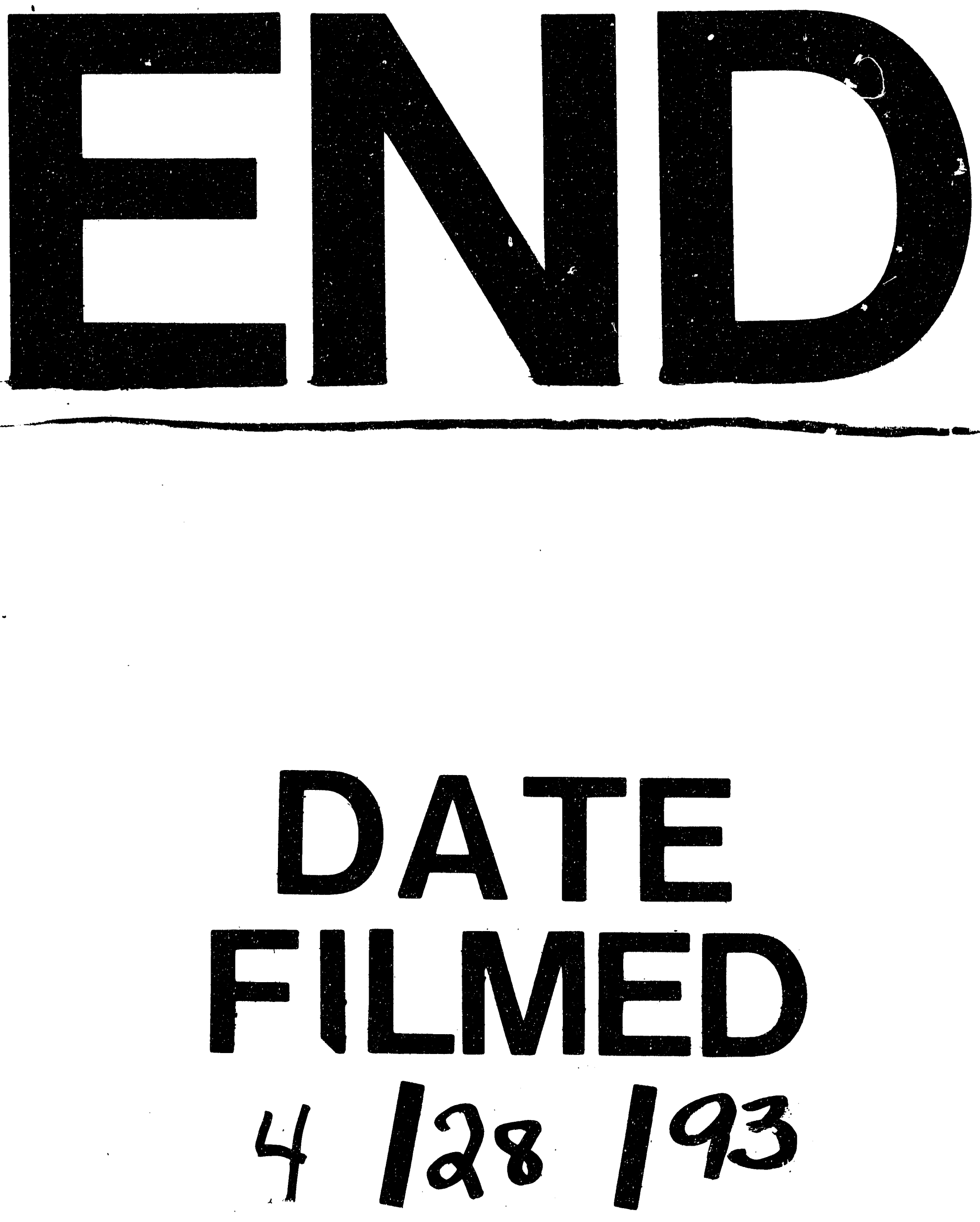


$$
+, \quad,=
$$

